kỹ thuật ESD cần rất nhiều yếu tố như: trang thiết bị, kinh nghiệm thực hành, vai trò của giải phẫu bệnh...

\section{KẾT LUẬN}

Nội soi da dày thường quy và sinh thiết làm mô bệnh học đóng vai trò quan trọng giúp phát hiện sớm ung thư dạ dày tại Việt Nam.

TÀl LIỆ THAM KHẢO

1. Sung $\mathbf{H}$, Ferlay $\mathbf{J}$, Siegel $\mathbf{R L}$, et al. Globocal cancer statistics 2020: GLOBOCAN estimates of incidence and mortality worldwide for 36 cancers in 185 countries. CA Cancer Journal Clinical 2021;71; 209-249

2. Kim 'SG, Park CM, Lee NR, et al. Long-term clinical outcomes of endoscopic submucosal dissection in patients with early gastric cancer: A prospective multicenter cohort study. Gut and Liver 2018;12(4): 402-410

3. Yao K. The endoscopic diagnosis of early gastric cancer. Annals of Gastroenterology 2013;26: 11-22

4. Nishitani M, Yoshida N, Tsuji S, et al. Optimal number of endoscopic biopsies for diagnosis of early gastric cancer. Endoscopy International Open 2019;07: E1683-E1690

5. Sung JK. Diagnosis and management of gastric dysplasia. Korean J Intern Med 2016;31: 201-209

\title{
ĐÁNH GIÁ KẾT QUẢ ĐÎ̀U TRI VIÊM KẾT MẠC Dİ ỨNG THỂ THEO MÙA VÀ QUANH NĂM BẰNG NƯỚC MẮT NHÂN TẠO KHÔNG Có CHẤT BẢO QUẢN
}

\section{TÓM TẮT}

Hình thái lâm sàng viêm kết mạc di ứng theo mùa, quanh năm của bệnh viêm kết mạc dị ứng thường bị bỏ qua, dễ nhầm lâ̂n với triêu chứng măt kích ứng tam thời với gió, bụi hay viêm kết mạc do các yếu tố nhiễm trùng.Thực tế khi được chẩn đoán, bệnh nhân sẽ được điêu trị ngay bằng các thuốc kháng dị ứng trong khi chưa thực sự cần thiết.Nghiên cứu mô tả, can thiệp lâm sàng so sánh trước sau và không đối chứng trền 62 đối tượng được chẩn đoán xác định là viêm kết mac di ứng theo mùa và viêm kết mạc dị ứng quanh nămtại Bệnh viện Mắt Nghệ An từ tháng 4/1999 đến tháng $8 / 2020$. Bệnh nhân được điêuu trị bằng nước mắt nhân tạo không có chất bảo quản (Vismed) nhỏ mắt ngày 4 lần, theo dõi trong 3 tháng tai các thời điểm sau 1 tuần, sau 1 tháng và sau 3 tháng điêuu trị. Kết quả cho thấy điểm trung bình các triệu chứng (ngứa, sợ ánh sáng, chảy nước mắt, sưng nề mi, cương tụ kết mạc và viêm chấm biểu mô) đêu giảm dần có ý nghĩa thống kê sau 1 tuần, 1 tháng và sau 3 tháng điêu trị bằng nước mắt nhân tạo Vismed $(p<0,001)$. Tỷ lệ bệnh nhân khỏi bênh tăng lên từ sau 1 tuần điều trị, đêến sau 3 tháng điều trị hầu hết bệnh nhân đều khỏi bệnh, sau 3 tháng điều trị chỉ còn 3 bệnh nhân $(4,8 \%)$ đớ các triệu chứng của bệnh. Nghiên cứu đã chî ra được hiệu quả của nước mắt nhân tạo không có chất bảo quản trong việc điều trị viêm kêt mạc dị ứng thểtheo mùa và quanh năm.

Từ khóa: Viêm kết mạc dị ứng, Viêm kết mạc dị ứng theo mùa, Viêm kết mạc dị ứng quanh năm, nước mắt nhân tạo, chất bảo quản.

\footnotetext{
*Sở Y tế Nghê An,

**Bệnh viền Mắt Nghệ An

Chịu trách nhiệm chính: Nguyễn Hữu Lê

Email: lebvmna@gmail.com

Ngày nhận bài: 9.8.20251

Ngày phản biện khoa học: 1.10 .2021

Ngày duyệt bài: 11.10.2021
}

\section{SUMMARY \\ EFICACY OF NON-PRESERVATIVE \\ ARTIFICIAL TEARS IN THE TREATMENT OF SEASONAL ALLERGIC CONJUNCTIVITIS AND PERENNIAL ALLERGIC CONJUNTIVITIS}

The clinical form of seasonal, perennial allergic conjunctivitis of allergic conjunctivitis is often overlooked, easily confused with transient irritation of the eye with wind, dust, or conjunctivitis caused by infectious factors. In fact, when diagnosed, patients will be treated immediately with anti-allergic drugs while not really needed. Descriptive study, clinical intervention comparing before, after and without control on 62 subjects with confirmed diagnosis of seasonal allergic conjunctivitis and perennial allergic conjunctivitis at Nghe An Eye Hospital since May. April 1999 to August 2020. Patients were treated with artificial tears without preservatives (Vismed) eye drops 4 times a day, followed up for 3 months at the time points after 1 week, after 1 month and after 3 months of treatment. The results showed that the mean scores of symptoms (itching, photophobia, lacrimation, eyelid swelling, conjunctival edema and punctate epithelitis) all decreased statistically significantly after 1 week, 1 month and after 3 months of treatment with Vismed artificial tears $(p<0.001)$. The rate of patients recovered increased from 1 week of treatment, to after 3 months of treatment, most of the patients were cured, after 3 months of treatment only 3 patients $(4.8 \%)$ were relieved of their symptoms. Research has shown the effectiveness of non-preservative artificial tears in the treatment of seasonal and perennial allergic conjunctivitis.

Keywords: Allergic conjunctivitis, Seasonal allergic conjunctivitis, Perennial allergic conjunctivitis, artificial tears, preservatives.

\section{I. ĐẶT VẤN ĐỀ}

Viêm kết mạc dị ứng (VKMDU) là một bệnh 
mắt di ứng mạn tính tại kết mạc nhãn cầu. Bệnh là hệ quả của phản ứng quá mẫn tức thời Type I của bề mă̆t kết giác mạc với các kháng nguyên trong không khí và môi trường. Bệnh biểu hiện các mức độ nặng nhẹ khác nhau[1].Các hình thái lâm sàng của bệnh viêm kết mạc dị ứng bao gồm: viêm kết mạc dị ứng theo mùa, viêm kết mạc dị ứng quanh năm, viêm kết mạc mùa xuân, viểm kết mạc chàm cơ địa, viêm kết mạc có nhú gai khổng lồ[1].

Hình thái lâm sàng viêm kết mạc dị ứng theo mùa, quanh năm thường bị bỏ qua và dễ nhầm lẫn với triệu chứng mắt kích ứng tạm thời với gió, bụi hay viêm kết mạc do các yểu tố nhiễm trùng.Một thực trạng phổ biến là sau khi được phát hiện, chẩn đoán viêm kết mạc dị ứng theo mùa hay quanh năm, bệnh nhân sẽ được điều trị ngay bằng các thuốc kháng dị ứng. Trong khi đối với các thể này bệnh chưa cần thiết phải dùng các thuốc kháng dị ứng đặc hiệu ngay lập tức. Với tính chất mạn tính việc dùng thuốc kéo dài sẽ kéo theo nguy cơ xuất hiện các tác dụng phụ của thuốc, của các chất bảo quản gây nên như khô mắt, tăng nhãn áp...đe dọa đến tính ổn định bề mặt nhãn câu và chức năng thị giác $[2,3]$. Nhiều tác giả đều khuyến cáo rằng: với viêm kết mạc dị ứng thể theo mùa và quanh năm việc điểu trị ban đầu chỉ cần cách ly tránh tiếp xúc, cùng với rửa sạch dị nguyên, đặc biệt là dùng nước mắt nhân tạo. Khi đó nước mắt nhân tạo trở thành dung dịch rửa trôi, đóng vai trò tạo nên một hàng rào ngăn cách giữa bề mặt nhã̃n câu với sự xâm nhập của các yếu tố di nguyên. Nước mắt nhân tạo thúc đẩy hàn gắn tổn thương biểu mô kết giác mạc (hậu quả gây nên do viêm và phản ứng miễn dịch dị ứng), thuyên giảm các triệu chứng làm cho bệnh nhân trở nên dễ chịu[ $[4,5]$. Chúng tôi tiến hành nghiên cứu nhằm đánh giá kết quả điều trị viêm kết mạc dị ứng thể theo mùa, quanh năm bằng nước mắt nhân tạo không có chất bảo quản

\section{KẾT QUẢ NGHIÊN CỨU}

\section{Bảng 1. Triệu chứng ngứa tại các thời điểm điều trị}

\begin{tabular}{|c|c|c|c|c|c|c|}
\hline \multirow{2}{*}{$\begin{array}{c}\text { Triếu } \\
\text { chứng } \\
\text { ngứa }\end{array}$} & \multicolumn{6}{|c|}{ Thời điếm theo dõi n (\%) } \\
\cline { 2 - 7 } & $\begin{array}{c}\text { SKMu 1 tuân } \\
\text { VKMDU } \\
\text { theo mùa }\end{array}$ & $\begin{array}{c}\text { VKMDU } \\
\text { quanh năm }\end{array}$ & $\begin{array}{c}\text { VKMDU 1 tháng } \\
\text { theo mùa }\end{array}$ & $\begin{array}{c}\text { VKMDU } \\
\text { quanh năm }\end{array}$ & $\begin{array}{c}\text { VKMDU } \\
\text { theo mùa }\end{array}$ & $\begin{array}{c}\text { VKMDU } \\
\text { quanh năm }\end{array}$ \\
\hline Không có & $6(9,7)$ & $1(1,6)$ & $25(40,3)$ & $6(9,7)$ & $47(75,8)$ & 12 \\
\hline Nhe & $23(37,1)$ & $7(11,3)$ & $22(35,5)$ & $6(9,7)$ & $2(3,2)$ & $1(1,6)$ \\
\hline Trung bình & $18(29,0)$ & $4(6,5)$ & $2(3,2)$ & $1(1,6)$ & - & - \\
\hline Nặng & $2(3,2)$ & $1(1,6)$ & - & - & - & - \\
\hline Tống & $\mathbf{4 9 ( 7 9 , 0 )}$ & $\mathbf{1 3}(\mathbf{2 1}, \mathbf{0})$ & $\mathbf{4 9 ( 7 9 , 0 )}$ & $\mathbf{1 3 ( 2 1 , 0 )}$ & $\mathbf{4 9 ( 7 9 , 0 )}$ & $\mathbf{1 3 ( 2 1 , 0 )}$ \\
\hline
\end{tabular}

Triệu chứng ngứa giảm dần theo thời gian điều trị. Sau 1 tuần tỷ lệ còn triệu chứng ngứa mức độ
II. ĐỐI TƯƠNGG VÀ PHƯƠNG PHÁP NGHIÊN CỨU

Đối tượng. Bao gồm 62 bệnh nhân chẩn đoán viêm kết mạc dị ứng thể theo mùa, thể quanh năm từ 6 tuổi trở lên đến khám và điều trị ngoại trú tại Bệnh viện Mắt Nghệ An từ tháng 4/2019 đến tháng 8/2020.

\section{Phương pháp nghiên cứu}

Thiêt kế nghiên cứu: Nghiên cứu mô tả, can thiêp lâm sàng so sánh trước sau và không đối chứng. Những bệnh nhân chẩn đoán xác định viêm kết mạc dị ứng thể theo mùa và quanh năm được điều trị bằng nước mắt nhân tạo không chất bảo quản Vismed do hãng TRB CHEMEDICA tại Đức sản xuất. Nhỏ hai mắt ngày 4 lần, mỗi mắt 1 đến 2 giọt. Theo dõi trong 3 tháng với các mốc thời gian: sau 1 tuần, sau 1 tháng và sau 3 tháng điều trị.

Đánh giá đáp ứng điều trị dựa vào sự thuyên giảm triệu chứng cơ năng ngứa; các triệu chứng thực thể: sợ ánh sáng, chảy nước mắt, sưng nề mi và cương tụ kết mạc.

Địa điểm nghiên cứu: Khoa khám bệnh, bệnh viện Mắt Nghệ An từ tháng 4/2019 đến tháng $8 / 2020$

Cõ̃ mẫu và chọn mẫu: Chọ mẫu thuân tiên, ngẫu nhiên không xác suất. Tổng cộng có 62 bệnh nhân đủ tiêu chuẩn nghiên cứu được chọn.

Xử lý số liệu: Các bệnh án sau khi thu thập được làm sach, nhâp liêu bằng phần mềm Epidata 3.1 và xử lý số liệu bằng phân mềm SPSS 20.0.Áp dụng các phương pháp phân tích mô tả: tính tỷ lệ phần trăm, giá trị trung bình. Paired-Samples T Test được sử dụng để đánh giá hiệu quả điều trị sau 1 tuần, 1 tháng, 3 tháng. Khoảng tin cậy $\mathrm{CI}=95 \%$ và mức $\mathrm{p}$ có ý nghĩa thống kê $p=0,05$.

Đạo đức nghiên cứu: Đề tài được sự đồng ý và thông qua của Hội đồng đạo đức trong nghiên cứu y sinh học Trường Đại học $Y$ Dược Huế. 
nhe là $37,1 \%$ ở nhóm VKMDU theo mùa và $11,3 \%$ ở nhóm VKMDU quanh năm. Thời điểm sau 3 tháng điêu trị triệu chứng ngứa mức độ nhẹ chỉ còn 3,2\% bệnh nhân VKMDU theo mùa và 1,6\% bệnh nhân VKMDU quanh năm. Có 75,8\% bệnh nhân VKMDU theo mùa với 19,4\% bệnh nhân VKMDU quanh năm mất hẳn triệu chứng ngứa.

Bảng 2. Triệu chứng sợ ánh sáng tại các thời điểm điều trị

\begin{tabular}{|c|c|c|c|c|c|c|}
\hline \multirow{3}{*}{$\begin{array}{l}\text { Triệu chứng } \\
\text { sợ ánh sáng }\end{array}$} & \multicolumn{6}{|c|}{ Thời điếm theo dõi n (\%) } \\
\hline & \multicolumn{2}{|c|}{ Sau 1 tuần } & \multicolumn{2}{|c|}{ Sau 1 tháng } & \multicolumn{2}{|c|}{ Sau 3 tháng } \\
\hline & $\begin{array}{l}\text { VKMDU } \\
\text { theo mùa }\end{array}$ & $\begin{array}{c}\text { VKMDU } \\
\text { quanh năm }\end{array}$ & $\begin{array}{l}\text { VKMDU } \\
\text { theo mùa }\end{array}$ & $\begin{array}{l}\text { VKMDU } \\
\text { quanh năm }\end{array}$ & $\begin{array}{l}\text { VKMDU } \\
\text { theo mùa }\end{array}$ & $\begin{array}{c}\text { VKMDU } \\
\text { quanh năm }\end{array}$ \\
\hline Không có & $42(67,7)$ & $12(19,4)$ & $46(74,2)$ & $13(21,0)$ & $48(77,4)$ & $13(21,0)$ \\
\hline Nhẹ & $4(6,5)$ & $1(1,6)$ & $3(4,8)$ & - & $1(1,6)$ & - \\
\hline Trung bình & $3(4,8)$ & 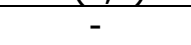 & - & - & - & - \\
\hline Nặng & & - & - & 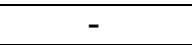 & - & - \\
\hline Tống & $49(79,0)$ & $13(21,0)$ & $49(79,0)$ & $13(21,0)$ & $49(79,0)$ & $13(21,0)$ \\
\hline
\end{tabular}

Triệu chứng sợ ánh sáng cũng giảm rõ rệt tại các thời điểm điêuu trị. Ngay sau 1 tuần điều trị tỷ lệ sợ ánh sáng mức độ trung bình giảm xuống còn $4,8 \%$ và mức độ nhẹ còn $8,1 \%$ ở hai nhóm. Sau 1 tháng còn $4,8 \%$ và chỉ có $1,6 \%$ ở thời điểm sau 3 tháng điều trị.

Bảng 3. Triệu chứng chảy nước mắt tại các thời điểm điều trị

\begin{tabular}{|c|c|c|c|c|c|c|}
\hline \multirow{3}{*}{$\begin{array}{c}\text { Triệu chứng } \\
\text { chảy nước } \\
\text { mắt }\end{array}$} & \multicolumn{6}{|c|}{ Thời điếm theo dõi n (\%) } \\
\hline & \multicolumn{2}{|c|}{ Sau 1 tuân } & \multicolumn{2}{|c|}{ Sau 1 tháng } & \multicolumn{2}{|c|}{ Sau 3 tháng } \\
\hline & $\begin{array}{l}\text { VKMDU } \\
\text { theo mùa }\end{array}$ & $\begin{array}{c}\text { VKMDU } \\
\text { quanh năm }\end{array}$ & $\begin{array}{l}\text { VKMDU } \\
\text { theo mùa }\end{array}$ & $\begin{array}{c}\text { VKMDU } \\
\text { quanh năm }\end{array}$ & $\begin{array}{l}\text { VKMDU } \\
\text { theo mùa }\end{array}$ & $\begin{array}{c}\text { VKMDU } \\
\text { quanh năm }\end{array}$ \\
\hline Khôn & $33(53,2)$ & $9(14,5)$ & $45(72,6)$ & $10(16,1)$ & $49(79,0)$ & $13(21,0)$ \\
\hline & $15(2$ & $4(6,5)$ & $4(6,5)$ & $3(4,8)$ & - & - \\
\hline Tru & $1(1,6$ & - & - & -1 & - & - \\
\hline & & 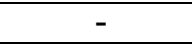 &  & 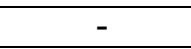 & - & - \\
\hline Tống & $49(79,0)$ & $13(21,0)$ & $49(79,0)$ & $13(21,0)$ & $49(79,0)$ & $13(21,0)$ \\
\hline
\end{tabular}

Triệu chứng chảy nước mắt cũng giảm từ sau 1 tuần điều trị trở đi với $24,2 \%$ ở nhóm VKMDU theo mùa và $6,5 \%$ ở nhóm VKMDU quanh năm. Sau 1 tháng tỷ lệ này giảm rõ rệt $(6,5 \%$ nhóm VKMDU theo mùa, $4,8 \%$ ở nhóm quanh năm) và sau 3 tháng điêu trị thì không có bệnh nhân nào còn triệu chứng chảy nước mắt.

Bảng 4. Triệu chứng sưng nề mi mắt tại các thời điểm điều trị

\begin{tabular}{|c|c|c|c|c|c|c|}
\hline \multirow{3}{*}{$\begin{array}{l}\text { Triệu chứng } \\
\text { sưng nề mî }\end{array}$} & \multicolumn{6}{|c|}{ Thời điếm theo dõi n (\%) } \\
\hline & \multicolumn{2}{|c|}{ Sau 1 tuần } & \multicolumn{2}{|c|}{ Sau 1 tháng } & \multicolumn{2}{|c|}{ Sau 3 tháng } \\
\hline & $\begin{array}{l}\text { VKMDU } \\
\text { theo mùa }\end{array}$ & $\begin{array}{l}\text { VKMDU } \\
\text { quanh năm }\end{array}$ & $\begin{array}{l}\text { VKMDU } \\
\text { theo mùa }\end{array}$ & $\begin{array}{c}\text { VKMDU } \\
\text { quanh năm }\end{array}$ & $\begin{array}{l}\text { VKMDU } \\
\text { theo mùa }\end{array}$ & $\begin{array}{c}\text { VKMDU } \\
\text { quanh năm }\end{array}$ \\
\hline Không có & $34(54,8)$ & $9(14,5)$ & $45(72,6)$ & $12(19,4)$ & $49(79,0)$ & $13(21,0)$ \\
\hline Nhe & $14(22,6)$ & $4(6,5)$ & $4(6,5)$ & $1(1,6)$ & - & - \\
\hline Trung bình & $1(1,6)$ & - & - & - & - & - \\
\hline Nặng & - & - & - & - & - & - \\
\hline Tống & $49(79,0)$ & $13(21,0)$ & $49(79,0)$ & $13(21,0)$ & $49(79,0)$ & $13(21,0)$ \\
\hline
\end{tabular}

Triệu chứng sưng nề mi giảm sau 1 tuần điêuu trị, mức độ sưng nề mi nhe giảm xuống còn $22,6 \%$ nhóm VKMDU theo mùa, 6,5\% ở nhóm VKMDU quanh năm. Sau 1 tháng điêu trị thì tỷ lệ này giảm hẳn còn $8,1 \%$ ở cả 2 nhóm và sau 3 tháng điều trị thì tất cae các bệnh nhân đêu hết triệu chứng sưng nề mi.

Bảng 5. Triệu chứng cương tụ kết mạc tại các thời điểm điều trị

\begin{tabular}{|c|c|c|c|c|c|c|}
\hline \multirow{3}{*}{$\begin{array}{l}\text { Triệu chứng } \\
\text { cương tụ } \\
\text { kết mạc }\end{array}$} & \multicolumn{6}{|c|}{ Thời điếm theo dõi n (\%) } \\
\hline & \multicolumn{2}{|c|}{ Sau 1 tuần } & \multicolumn{2}{|c|}{ Sau 1 tháng } & \multicolumn{2}{|c|}{ Sau 3 tháng } \\
\hline & $\begin{array}{l}\text { VKMDU } \\
\text { theo mùa }\end{array}$ & $\begin{array}{c}\text { VKMDU } \\
\text { quanh năm }\end{array}$ & $\begin{array}{l}\text { VKMDU } \\
\text { theo mùa }\end{array}$ & $\begin{array}{c}\text { VKMDU } \\
\text { quanh năm }\end{array}$ & $\begin{array}{l}\text { VKMDU } \\
\text { theo mùa }\end{array}$ & $\begin{array}{c}\text { VKMDU } \\
\text { quanh năm }\end{array}$ \\
\hline Không c & $15(24,2)$ & $3(4,8)$ & $39(62,9)$ & $9(14,5)$ & $49(79,0)$ & $13(21,0)$ \\
\hline Nhẹ & $31(50,0)$ & $8(12,9)$ & $10(16,1)$ & $4(6,5)$ & - & - \\
\hline Trung bình & $3(4,8)$ & $2(3,2)$ & - & - & - & - \\
\hline Nặng & & - & - & 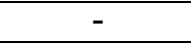 & - & - \\
\hline Tống & $49(79,0)$ & $13(21,0)$ & $49(79,0)$ & $13(21,0)$ & $49(79,0)$ & $13(21,0)$ \\
\hline
\end{tabular}


Tính tổng cho 2 nhóm bệnh nhân sau 1 tuân điều trị triệu cương tụ kết mạc mức độ trung bình giảm còn $8 \%$ mức độ nhẹ là $62,9 \%$, và sau 1 tháng điều trị thì mức độ nhẹ giảm hẳn còn $22,6 \%$. Triệu chứng này mất hẳn sau 3 tháng điều trị.

Bảng 6. Test thời gian vỡ phim nước mắt (BUT)

\begin{tabular}{|c|c|c|c|c|}
\hline \multirow{2}{*}{ Test BUT hai mắt } & \multicolumn{5}{|c|}{ Thời điếm theo dõi n (\%) } \\
\cline { 2 - 5 } & Lúc vào viện & Sau 1 tuần & Sau 1 tháng & Sau 3 tháng \\
\hline Khô măt & $49(79,0)$ & $42(67,7)$ & $22(35,5)$ & $5(8,1)$ \\
\hline Bình thường & $13(21,0)$ & $20(32,3)$ & $40(64,5)$ & $57(91,9)$ \\
\hline $\mathbf{P}$ & & $<0,0001$ & 0,003 & 0,233 \\
\hline
\end{tabular}

Tỷ lệ bệnh nhân bị khô cả hai mắt giảm một cách có ý nghĩa thống kê sau 1 tuần $(p<0,0001)$ và sau 1 tháng điêu trị $(p=0,003)$. Tuy nhiên tỷ lệ khô mắt giảm sau 3 tháng điêu trị không có ý nghĩa thống kê $(\mathrm{p}=0,233)$.

Bảng 7. Kết quả điều trị sau 1 tuần, 1 tháng và 3 tháng

\begin{tabular}{|c|c|c|c|c|c|c|}
\hline \multirow{3}{*}{$\begin{array}{l}\text { Hiệu quả } \\
\text { điêuu trị }\end{array}$} & \multicolumn{6}{|c|}{ Thời điếm theo dõi n (\%) } \\
\hline & \multicolumn{2}{|c|}{ Sau 1 tuần } & \multicolumn{2}{|c|}{ Sau 1 tháng } & \multicolumn{2}{|c|}{ Sau 3 tháng } \\
\hline & $\begin{array}{l}\text { VKMDU } \\
\text { theo mùa }\end{array}$ & $\begin{array}{c}\text { VKMDU } \\
\text { quanh năm }\end{array}$ & $\begin{array}{l}\text { VKMDU } \\
\text { theo mùa }\end{array}$ & $\begin{array}{c}\text { VKMDU } \\
\text { quanh năm }\end{array}$ & $\begin{array}{l}\text { VKMDU } \\
\text { theo mùa }\end{array}$ & $\begin{array}{c}\text { VKMDU } \\
\text { quanh năm }\end{array}$ \\
\hline Khỏi bệnh & $(11,3)$ & $1(1,6)$ & $25(40,3)$ & $7(11,3)$ & $47(75,8)$ & $12(19,4)$ \\
\hline 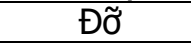 & $42(67,7)$ & $12(19,4)$ & $24(38,7)$ & $6(9,7)$ & $2(3,2)$ & $1(1,6)$ \\
\hline Không khỏ & $=$ & - & 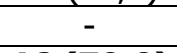 & - & 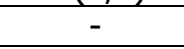 & 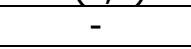 \\
\hline Tống & $49(79,0)$ & $13(21,0)$ & $46(79,0)$ & $13(21,0)$ & $49(79,0)$ & $13(21,0)$ \\
\hline
\end{tabular}

Trong tổng số 62 bệnh nhân, sau một tuần điều trị số bệnh nhân VKMDU theo mùa khỏi bệnh chiếm 7 người $(11,3 \%)$ và đõ chiếm 42 người $(67,7 \%)$; số bệnh VKMDU quanh năm khỏi bệnh chỉ chiếm 1 người với tỷ lệ 1,6\% và đỡ chiếm 12 người (19,4\%), không có bệnh nhân nào không khỏi sau một tuần điều trị trở đi. Và tỷ lệ các ca bệnh khỏi và đỡ cũng tăng dần sau 1 tháng và sau 3 tháng theo dõi điều trị.

Bảng 8. Điểm trung bình các triệu chứng lâm sàng theo dôi sau thời gian điều trị

\begin{tabular}{|c|c|c|c|c|}
\hline \multirow{2}{*}{ Triệu chứng } & \multicolumn{4}{|c|}{ Thời điếm theo dối } \\
\cline { 2 - 5 } Ngứa & Lúc vào viện & Sau 1 tuần & Sau 1 tháng & Sau 3 tháng \\
\hline Điếm trung bình & $2,06(0-3)$ & $1,34(0-3)$ & $0,55(0-2)$ & $0,05(0-1)$ \\
\hline$p$ & & $<0,0001$ & $<0,0001$ & $<0,0001$ \\
\hline Sợ ánh sáng & & & & \\
\hline Điểm trung bình & $0,38(0-2)$ & $0,16(0-2)$ & $0,04(0-1)$ & $0,02(0-1)$ \\
\hline$p$ & $<0,0001$ & $<0,0001$ & $<0,0001$ \\
\hline Chảy nước mắt & & & & \\
\hline Điếm trung bình & $0,71(0-2)$ & $0,34(0-2)$ & $0,11(0-1)$ & 0,00 \\
\hline$p$ & & $<0,0001$ & $<0,0001$ & - \\
\hline Sứng nề mi & & & & 0,00 \\
\hline Điếm trung bình & $0,60(0-2)$ & $0,32(0-2)$ & $0,08(0-1)$ & - \\
\hline$p$ & & $<0,0001$ & $<0,0001$ & \\
\hline Cương tụ kết mạc & & & & 0,000 \\
\hline Điếm trung bình & $1,32(0-3)$ & $0,79(0-2)$ & $0,23(0-1)$ & - \\
\hline$p$ & & $<0,0001$ & $<0,0001$ & \\
\hline$p$ & &
\end{tabular}

Điểm trung bình của tất cả các triệu chứng ngứa, sợ ánh sáng, chảy nước mắt, sưng nề mi, cương tụ kết mạc và viêm chấm biểu mô đểu giảm có ý nghĩa thống kê $(p<0,0001)$ từ sau 1 tuần, 1 tháng và sau 3 tháng theo dõi điều trị.

\section{BÀN LUÂ̂N}

Nghiên cứu chỉ ra rằng đa số bệnh nhân có triệu chứng ngứa lúc vào viện mức độ trung bình và nặng, tuy nhiên triệu chứng này giảm một cách rõ rệt sau 1 tuần điều trị $(p<0,001)$, sau 1 tháng và sau 3 tháng triệu chứng ngứa hầu như giảm hoàn toàn $(p<0,001)$. Điểm trung bình của triệu chứng ngứa tại thời điểm đến khám là 2,06; sau 1 tuần điều trị bằng nước mắt nhân tạo điểm trung bình giảm còn 1,34; sau 1 tháng và sau 3 tháng điểm trung bình giảm tương ứng là 0,55 và 0,05 . Kết quả của nghiên cứu tương 
đồng với nghiên cứu của nhóm tác giả Umit Kamis và cộng sự thử nghiệm đánh giá hiệu quả của nước mắt nhân tạo trong điều trị VKMDUTM, điểm trung bình của triệu chứng ngứa giảm từ 2,59 lúc vào viện giảm còn 2,21 điểm $(p=0,003)$ sau 1 tuần điêu trị và sau 1 tháng giảm còn 1,98 điểm sau 1 tháng điều trị $(p<0,001)[6]$.

Nghiên cứu cho thây lúc mới vào viện đa phần bệnh nhân có triệu chứng sợ ánh sáng ở mức độ nhẹ, triệu chứng này cũng nhanh chóng hết sau 1 tuần điều trị. Điểm trung bình giảm có ý nghĩa thống kê từ 0,38 lúc mới vào viện xuống còn 0,16 điểm sau điều trị 1 tuần $(p<0,001)$. Triệu chứng sợ ánh sáng thuyên giảm nhanh chúng tôi cho rẳng do lúc vào viện biểu hiện mức độ nhe và tương quan với triệu chứng thực thể viêm chấm nông biểu mô không có nhiều nên chỉ sau thời gian điều trị ngắn 1 tuần nhờ tác dụng của thuốc nhỏ mắt Vismed.

Bệnh nhân ban đầu mới đến khám có mức độ chảy nước mắt từ nhe đến trung bình, triệu chứng này cũng giảm một cách có ý nghĩa thống kê sau 1 tuần điêu trị, sau 1 tháng điêu trị thì giảm hoàn toàn. Điểm trung bình của triệu chứng chảy nước mắt giảm từ 0,71 lúc vào xuống còn 0,34 sau 1 tuần điều trị và 0,11 sau 1 tháng điều trị $(p<0,001)$. Kết quả này cũng tương tự với nghiên cứu của Umit Kamis và cộng sự, điểm trung bình giảm từ 1,29 lúc mới vào viện, sau 1 tuần điều trị giảm còn 1,23 điểm và sau 1 tháng giảm còn 1,12 điểm $(p<0,001)$.

Nghiên cứu cho thấy về hiệu quả điều trị điểm trung bình từ 0,60 lúc mới vào viện giảm còn 0,32 sau 1 tuần điều trị và giảm còn 0,08 sau 1 tháng $(p<0,001)$. Hiệu quả điều trị trong nghiên cứu này cao hơn so với nghiên cứu của Umit Kamis, điểm trung bình từ 0,59 lúc vào viện giảm còn 0,58 sau 1 tuần điêu trị và giảm còn 0,5 sau 1 tháng điều trị $(p<0,001)$. Điều này có thể lý giải do tại thời điểm vào viện đa phần bệnh nhân có triệu chứng chủ yếu ở mức độ nhẹ và trung bình nên hiệu quả điêuu trị cao hơn [6]. Bệnh nhân đến khám chủ yếu có mức độ bệnh nhè và trung bình. Điểm trung bình của triệu chứng cũng giảm một cách có ý nghĩa thống kê sau điều trị từ 1,32 giảm còn 0,79 sau 1 tuần điều trị và giảm còn 0,23 sau 1 tháng điêu trị $(p<0,001)$. Kết quả cũng tương tự với nghiên cứu của Umit Kamis điểm trung bình cũng giảm từ 2,01 còn 1,78 sau 1 tuần điều trị và còn 1,49 sau 1 tháng điêu trị bằng nước mắt nhân tạo $(p<0,001)$. Tất cả các dấu hiệu lâm sàng đều có xu hướng giảm về mức độ và hết hẳn từ sau khi điều trị 1 tuần cho đến 1 tháng điêu trị. Kết quả này chứng minh nước mắt nhân tạo có hiệu quả trong việc làm giảm các triệu chứng cơ nằng và thực thể một cách có ý nghĩa thống kê.

Sau điều trị bằng nước mắt nhân tạo 1 tuần tỷ lệ khô mắt giảm còn $67,7 \%(p<0,001)$, sau 1 tháng tỷ lệ khô mắt giảm còn $35,5 \%$ và sau 3 tháng tỷ lệ khô mắt giảm còn $8,1 \%(p=0,233)$. Nước mắt nhân tạo có hiệu quả giúp làm giảm khô mắt đặc biệt trong vòng 1 tháng đầu điêu trị một cách có ý nghĩa thống kê, tuy nhiên sau 3 tháng điều trị thì tỳ không có ý nghĩa thống kê nữa, điều này có thể lý giải do sau 1 tháng điều trị tình trạng bệnh đã đã ổn định và hồi phục hoàn toàn[7].

\section{KẾT LUẬN}

Điểm trung bình các triệu chứng (ngứa, sợ ánh sáng, chảy nước mắt, sưng nề mi, cương tụ kết mạc và viêm chấm biểu mô) đều giảm dần có ý nghĩa thống kê sau 1 tuần, 1 tháng và sau 3 tháng điều trị bằng nước mắt nhân tạo Vismed $(p<0,001)$.

Tý lệ bệnh nhân khỏi bệnh tăng lên từ sau 1 tuần điều trị, đến sau 3 tháng điều trị hầu hết bệnh nhân đều khỏi bệnh, sau 3 tháng điều trị chỉ còn 3 bệnh nhân $(4,8 \%)$ đõ các triệu chứng của bệnh. Không có bệnh nhân nào hoàn toàn không khỏi sau điều trị.

\section{TÀI LIẸU THAM KHẢO}

1. Kubaisi, B., K. Samra, and S. Syeda, Ocular Allergy: an Updated Review. J Allergy Immunol, 2017. 1: p. 002.

2. Tôn Thị Kim Thanh và cộng sự, Viêm kết mạc dị ứng. Bài giảng nhãn khoả bán phần trước nhắn cầu, 2005: p. $73-82$.

3. Hoàng Thị Minh Châu, Tiếp cận học tập bệnh Viêm kêt giác mac mùa xuân. 1982, Bộ y tế: Trường đại học y khoa Hà nội.

4. Bilkhu, P.S., J.S. Wolffsohn, and S.A. Naroo, A review of non-pharmacological and pharmacological management of seasonal and perennial allergic conjunctivitis. Contact Lens and Anterior Eye, 2012. 35(1): p. 9-16.

5. Hiroyuki Yazu, et al., Efficacy and safety of an eye wash solution in allergic conjunctivitis after conjunctival allergen challenge. Annals of Allergy, Asthma \& Immunology, 2016. 117: p. 550-572.

6. Kamis, U., et al., Comparison of the efficacy of olopatadine hydrochloride $0.1 \%$ ophthalmic solution and artificial tears in seasonal allergic conjunctivitis. Acta Ophthalmol Scand, 2006. 84(1): p. 148-9.

7. Bilkhu, P.S., et al., Effectiveness of nonpharmacologic treatments for acute seasonal allergic conjunctivitis. Ophthalmology, 2014. 121(1): p. $72-78$. 